\title{
From playing to designing: Enhancing educational experiences with location-based mobile learning games
}

\author{
Roger Edmonds and Simon Smith \\ University of South Australia
}

\begin{abstract}
This paper presents research into the benefits and implementation strategies of integrating location-based mobile learning games in higher education courses to enhance educational experiences. Two approaches were studied: learning by playing, and learning by designing. In the first, games were developed for undergraduate courses in four discipline areas, introduced during lectures, and played by students during a tutorial, as a self-guided activity or field excursion. In the second, students designed and developed their own prototype games as an educational activity to explore pedagogical strategies in personalised learning. Observations were made as students played and designed games. Online surveys, focus groups, and game analytics were used to help understand player behaviour and discover satisfaction rates, engagement, and the impact on learning outcomes. Results indicate that both the playing and self-designing of location-based mobile learning games can deliver active, engaging, and authentic educational experiences for students, enhancing opportunities to interact with locations, mobile content, and with each other. The impact of design, implementation strategy, and support on a student's motivation for, and engagement with, the learning is discussed, along with the designing of games to offer an opportunity for students to personalise their learning and develop new ICT skills.
\end{abstract}

\section{Introduction}

Location-based learning is substantially extended by the integration of mobile technologies in which mobile devices can use location awareness features to support learners as they engage in contextual activities (Ardito et al., 2010; Priestnall, Brown, Sharples, \& Polmear, 2010). Location-based mobile learning games (LBMLGs) bring together four of the most popular and current eLearning trends: mobile learning, digital storytelling, gamification, and location-based learning (Johnson, Adams, Becker, Estrada, \& Freeman, 2015), to unlock educational content through storytelling, rich digital media, location-awareness, maps, augmented reality, and gamification strategies. They embrace characteristics of both mobile learning and game-based learning and as discussed in Wijers, Jonker, and Drijvers (2010), turn learning into a personal, engaging experience where surroundings are linked to educational content. Location-based mobile learning games can shift the focus from mere identification of content to interactive discovery that enhances and extends the way students experience learning from the environment and with each other (Edmonds \& Smith, 2016).

Several important studies have investigated methods of enhancing educational experiences with LBMLGs. Liu and Chu (2010) examined how ubiquitous games influenced English learning achievement and motivation through a context-aware learning environment, and demonstrated that they could achieve better learning outcomes and motivation as compared with a non-gaming learning approach that involved using printed materials and CD's. They also found a positive relationship between learning outcomes and motivation, as did Huizenga, Admiraal, Akkerman, and Ten Dam (2007) in their study on the learning effects, motivation, and collaboration of playing a mobile city game in which students acquire historical knowledge about the medieval city of Amsterdam. A review of LBMLGs by Avouris and Yiannoutsou (2012) commented on the need for further study into how their design (viz., narratives used, interaction modes, use of physical spaces, roles of players) impacts user experience and learning. Alnuaim, CalebSolly, and Perry (2012) identified that the main challenge for designers of LBMLGs is the successful integration into authentic educational activities that are relevant to a student's work to enrich the learning experience. Slussareff and Boháčková (2016) compared the effectiveness of knowledge acquisition and engagement from both learning by designing and learning by playing LBMLGs, and found that the active approach (designing) revealed a positive effect on knowledge acquisition. However, students can learn facts and engage with content very well, both through designing and playing. In another study, Hwang, Po-Han $\mathrm{Wu}$, Chen, and Tu (2016) concluded that an augmented reality mobile gaming approach which involved a 
learning system to detect the location of the students, guide them to find the target, and show them the corresponding learning tasks or materials, is able to improve student's learning attitudes and achievements. Our project has attempted to build on current research with a focus on the:

- $\quad$ benefits that playing LBMLGs has on enhancing student educational experiences, particularly engagement, motivation, and learning,

- benefits that instructional design of the LBMLG have on educational experiences,

- benefits to learning as a LBMLG student designer versus a player,

- challenges of implementing LBMLGs as an activity into courses

- broader issues of deploying LBMLGs into different courses across different disciplines.

\section{Background}

In 2014, as part of the digital learning strategy within the University of South Australia (UniSA), a core undergraduate course (Business and Society) was identified as an opportune environment to integrate blended learning activities. One of the nominated student activities involved a local field trip exploring nearby businesses to discover what their place in society may have been in the past and to reflect upon what it is likely to be now. In the past, students used pencils and paper to record their observations. An opportunity existed to use the prevalence of smart mobile devices amongst students as a motivator for learning. Sharples (2002) suggests that rather than seeing them as disruptive devices, educators should seek to exploit the potential of mobile technologies and find ways to put them to good use for the benefit of learning. In a study by Murphy, Farley, and Koronios (2013), it was found that $81 \%$ of students in UniSA owned a smart mobile phone, with 76\% using it for study. As Veelo (2007) points out, unlike a paper and pen exercise, smart mobile devices have special functionalities, such as multi-mediality, connectivity, and location awareness capabilities, which enable them to deliver educational content at the right place and the right time to support just-in-time pedagogy. Students are likely to become more motivated to learn, when the concepts are most meaningful to them.

Our strategy took these defining features of smartphones to construct the pilot LBMLG for the Business and Society students. We selected the Mobile Learning Academy platform to design and develop the game due to its applicability to higher education, ease of use, strong customer support, and popularity. We used its online Game Maker to build in digital storytelling via rich media. We created interactive learning tasks, for example, quizzes, physical item identification and photo taking, to encourage students to actively look for and find information whilst playing. We applied simple gamification strategies such as play limits and rewards associated with correct answers to quizzes to convert desired tasks into play tasks. The importance of gamification is highlighted by Sigala (2015) in her report on how the integration of funware through gamification can motivate users and generate meaningful experiential values and great motivational affordances, which in turn can lead to significant and distinguishable behavioural outcomes. The intention was that if the LBMLG activity in Business and Society was successful it could then act as a springboard to pilot future mobile learning activities and assist in streamlining processes required to integrate mobile learning methodologies within other courses across the university. Prototyping in this manner helps in testing technical feasibility, understanding teaching and learning requirements, testing, and evaluating (Rogers, Sharp, \& Preece, 2011).

Over 500 students played the pilot LBMLG in their first tutorial during courses delivered in the first and second half on 2014. The mobile app took the form of an urban game with the story of businesses in Adelaide's West-End at its base. Students formed small teams, and with the assistance of a tutor, walked along a secret trail interacting with content in the app and with the real-world locations it presented by GPS activation, guiding exploration of different enterprises within the West-End precinct. It allowed students to rediscover an area they already knew but from a very new and engaging perspective. Feedback received was very encouraging. Students indicated that they were now engaged in learning in a way that required them to deepen their thinking, knowledge, and understanding of their local environment. Within the 24 groups surveyed, $73 \%$ of students reported that the LBMLG was engaging and a fun way to learn, and 69\% reported that it assisted them to understand the concept. While the activity was primarily designed to achieve specific topic-related learning outcomes, it had the unintended positive effect of students getting to know each other and make friends within their tutorial group. Research has highlighted that if students 
make friends in their tutorials or courses, retention is improved (Baik, Naylor, \& Arkoudis, 2015; Buote et al., 2007; Knight, et al., 2012; Thomas, 2012). We acknowledge that it was not possible to isolate an innovative intervention like this game and link it directly with student retention or course evaluations. What was possible however was to report students' and course coordinators' satisfaction with the game and to explore whether or not the innovation was a "one hit wonder” or had the potential to be scaled up.

This impressive pilot provided a basis to begin connecting other courses with the mindset of Generation Mobile. It has extended the reach of LBMLGs into the teaching and learning structure of other courses progressively engaging more students, strengthening existing pedagogical approaches, and adding value to student learning. The success of this initiative can be measured by perceptions from the students recorded through online surveys and focus groups, and by the scaling up of the original implementation into eight other courses in the past 3 years. During 2016 we have supported 87 students and 16 staff across the university to design and develop more than 80 LBMLGs in seven undergraduate courses and one postgraduate course. The deployment has reached across four divisions: business, education, arts, and science. All LBMLGs have been delivered as mobile apps using the Mobile Learning Academy platform, which is available for anyone to use to create games at locations of their choosing with no prior programming experience required. The games that have been designed and developed within our project have to date been played over 1400 times.

\section{Design approach and research method}

\section{Study 1: Students as players}

From 2014 to 2016 discussions with course coordinators were arranged to translate their vision into requirements about how LBMLGs can deliver benefits whilst ensuring relevance and successful integration into courses. We encouraged course coordinators to look for opportunities where an existing activity in their course could be strengthened with a LBMLG that connected it to an authentic learning environment and where it could be shaped into a digital story. Results from the Business \& Society pilot showed that students remembered their experience and the content and became more interested in the activity if these factors were met. We applied an action research approach developed by Visscher-Voerman, Gustafson, and Plomp (1999) in which a process of analysis, design, development, implementation, and evaluation was followed to assure focus on the needs of the users and not just on the possibilities of mobile technology. The requirements were then translated into a conceptual model to capture what the game will do, how it will behave, its look and feel, interaction tasks, gamification style, and the appropriate inclusion of supporting rich media. A similar approach was applied by Cochrane (2014) to identify critical success factors for transforming pedagogy using mobile Web 2.0, and therefore allows for comparability of our results. In the period 2014 to 2016 we were able to successfully scale up the implementation of LBMLGs in seven additional courses as shown in Figure 1 below.

\begin{tabular}{|l|l|l|}
\hline Course & Year & Game \\
\hline $\begin{array}{l}\text { Business and } \\
\text { Society }\end{array}$ & 2014 & $\begin{array}{l}\text { Local Enterprises is an urban game with the story } \\
\text { of businesses in Adelaide's West-End at its base. } \\
\text { Students walk along a trail interacting with the } \\
\text { app and with the real-world locations it took them } \\
\text { to, exploring different enterprises in the West- } \\
\text { End. }\end{array}$ \\
\hline $\begin{array}{l}\text { International } \\
\text { Tourism }\end{array}$ & 2016 & $\begin{array}{l}\text { Masters students designed LBMLGs at different } \\
\text { destinations. The games (e.g., South Korean } \\
\text { Cultural Discovery) guide tourists to key } \\
\text { attractions in Melbourne, Sydney, Macau, } \\
\text { Beijing, and Seoul. }\end{array}$ \\
\hline $\begin{array}{l}\text { Australian } \\
\text { History }\end{array}$ & 2016 & $\begin{array}{l}\text { The Mystery of the Colonel's Ghost takes } \\
\text { students on an interactive walking trail around the } \\
\text { streets of Adelaide to find a secret message } \\
\text { hidden in its design by the city's founder Colonel } \\
\text { William Light. }\end{array}$ \\
\hline
\end{tabular}




\begin{tabular}{|l|l|l|}
\hline $\begin{array}{l}\text { ICT in } \\
\text { Learning } \\
\text { and } \\
\text { Teaching }\end{array}$ & 2016 & $\begin{array}{l}\text { The Protectors delivers a story about the history } \\
\text { of the Magill Campus. The campus has a secret to } \\
\text { guide the future of ICT in learning that can only } \\
\text { be discovered by playing the game. }\end{array}$ \\
\hline $\begin{array}{l}\text { Indigenous } \\
\text { Art, Culture } \\
\text { and Design }\end{array}$ & 2016 & $\begin{array}{l}\text { The course coordinator developed two self- } \\
\text { guided excursions at Adelaide/Tarndanyangga } \\
\text { and the SA Museum. This was the first trial of an } \\
\text { academic independently designing and } \\
\text { developing a LBMLG using resources from the } \\
\text { prototype framework developed by the project. }\end{array}$ \\
\hline $\begin{array}{l}\text { Health \& } \\
\text { Fitness }\end{array}$ & 2016 & $\begin{array}{l}\text { LBMLGhop was used to introduce students to } \\
\text { and play LBMLGs at two campuses. Over 40 } \\
\text { student games were developed. }\end{array}$ \\
\hline $\begin{array}{l}\text { Earth } \\
\text { Systems }\end{array}$ & 2016 & $\begin{array}{l}\text { The Geology of Hallett Cove is an interactive } \\
\text { walking trail to complement a traditional field } \\
\text { excursion. Students can play the game before, } \\
\text { during and after the excursion. }\end{array}$ \\
\hline $\begin{array}{l}\text { Engineering } \\
\text { Geology }\end{array} 2015$ & $\begin{array}{l}\text { The North Terrace Geological Trail takes students } \\
\text { on a self-guided field excursion to discover rocks } \\
\text { used in Adelaide's major cultural buildings. High } \\
\text { resolution 360 degree panoramic images are used. }\end{array}$ \\
\hline
\end{tabular}

Figure 1. Location-based mobile learning games designed and developed in 2014-2016

Games were generally introduced to students in a lecture, then played outdoors soon after as part of a tutorial or field excursion. We have been collecting data on the effectiveness of LBMLG in teaching and learning over a period of 3 years (2014, 2015, and 2016). The data collection has involved observing and chronicling actions of students as they played, followed by an online survey that included questions on demographics, support, mobile app functionality and contribution to teaching and learning. Data collected has been analysed to identify user experiences related to satisfaction rates, engagement, and learning outcomes. Focus group discussions conducted by independent student leaders followed to complement online survey responses and provide a better understanding of the games' impact on student motivation for and engagement with the learning process. Administration tools provided by the Mobile Learning Academy were applied to investigate and analyse player behaviour, namely, participation/completion rates, GPS traces, and responses to quiz questions. Uploaded photos and notes were reviewed to validate visits and participation in activities.

\section{Study 2: Students as designers and developers}

We also encouraged course coordinators to look for opportunities in their course for students to create their own LBMLGs. This way, students not only taught each other but also learnt by representing information in a completely new way, acquiring contemporary digital skills in the process. The team worked with the course coordinator and postgraduate students in an international tourism course and with the course coordinator and undergraduate students in a fitness and lifestyle management course.

\section{International tourism: Predicting markets and opportunities}

In the student's first assignment, an activity was included where students were required to think of themselves as tour operators who needed to develop a new tourism product. The design and development of a prototype LBMLG for a destination of their choice was presented as a key task. Students were asked to identify three specific attractions within their chosen destination and create LBMLGs to give tourists the opportunity to virtually visit the destination, interact with the multimedia content, and learn more about the location in an engaging way. During week 1 , students went outdoors to play a local LBMLG then returned to class where its design and development were deconstructed. In week 2, the creation of a LBMLG using the Mobile Learning Academy platform was demonstrated. Students then formed small teams, chose a destination, and began storyboarding the concept, scope, narratives, places, media, interactivity, and gameplay in a template provided. They were directed to online tutorials, infographics and a Prezi to assist this process. Each group received a director licence to the Mobile Learning Academy platform allowing 
them authoring access to the online GameMaker to digitise their game. Students had 3 weeks to conceptualise, design, and develop their own game with the availability of ongoing email support during this process. Five games were created (Figure 2). Direct observations, online surveys, and administration tools were used to collect and analysis data.

\begin{tabular}{|l|l|l|}
\hline Course & Year & Game \\
\hline $\begin{array}{l}\text { International } \\
\text { Tourism }\end{array}$ & 2016 & $\begin{array}{l}\text { Macau Time Attack } \\
\text { Players find out the secrets at three key } \\
\text { attractions in Macau designing routes and ways } \\
\text { to approach the three goals in limited time. }\end{array}$ \\
\hline $\begin{array}{l}\text { International } \\
\text { Tourism }\end{array}$ & 2016 & $\begin{array}{l}\text { South Korean Cultural Discovery } \\
\text { Guides tourists to key attractions in Seoul. They } \\
\text { find interesting places and at the same time find } \\
\text { out about its cultural history. }\end{array}$ \\
\hline $\begin{array}{l}\text { International } \\
\text { Tourism }\end{array}$ & 2016 & $\begin{array}{l}\text { Sydney Cultural Discovery } \\
\text { Tourists explore this multi-cultural city, } \\
\text { learning the romantic story of Mrs Macquarie's } \\
\text { Chair, photographing the splendid scenery and } \\
\text { are taken to Sydney central market. }\end{array}$ \\
\hline $\begin{array}{l}\text { International } \\
\text { Tourism }\end{array}$ & 2016 & $\begin{array}{l}\text { Cultural Hunt } \\
\text { A mystery tour. Files are missing from the State } \\
\text { Library. Tourists are recruited as cultural } \\
\text { hunters to recover the files. The librarian } \\
\text { suggests that there are clues in three locations. } \\
\text { Hunters - it's your showtime! }\end{array}$ \\
\hline $\begin{array}{l}\text { International } \\
\text { Tourism }\end{array}$ & 2016 & $\begin{array}{l}\text { Heart of Beijing } \\
\text { Introduces tourists to Tiananmen Square where } \\
\text { there is an amazing mixture of political, historic } \\
\text { and modern culture exposed at different } \\
\text { locations. }\end{array}$ \\
\hline by ind
\end{tabular}

Figure 2. Games developed by international tourism students

Fitness and lifestyle management

This course is undertaken by students whose graduate aspirations include teaching health and physical education, coaching, and physical activity and/or health promotion. We incorporated LBMLGs into existing pedagogical practices to engage students in personalised learning, and to extend their range of pedagogical strategies. We began by introducing students to how games could be used in fostering and encouraging health-enhancing movement, whether this be walking, and/or jogging by playing an existing game. We then engaged students across the cognitive, affective, and operational domains establishing key procedures and criteria for game design. Students independently formed small teams and used the resources developed in the project to design, develop, and play a prototype game which they trialled themselves. This activity was then extended to playing games designed by other teams to provide peer reflection and constructive feedback using evaluation criteria provided. More than 40 student self-designed games were developed.

\section{Results}

\section{Study 1: Students as players}

In total, there were 1,330 plays of 7 LBMLGs during 2016. Online surveys were completed by 162 players after playing.

The age ranges of students were, 80\% 18 to 25 years old, 13\% over the age of 25 and 7\% under 18. iPhones were used by $71 \%$, Android phones by $27 \%$, and $2 \%$ used other devices. The majority of students (71\%) had never played previously any kind of location-based mobile game before. Only 16\% had played other socially constructed location-based games on their mobile phone before (e.g., Geocaching, Foursquare etc). 
Student/staff support

Staff and student expectations, adoption, support, and guidance were managed through information sessions, quick reference guides, instructional videos, and face-to-face support while playing. Students needed little help in order to play the games. Only 6\% reported that they needed a lot or a great deal of support and guidance whereas $62 \%$ of them needed only a little help or none at all.

\section{Mobile app functionality}

The Mobile Learning Academy (MLA) app was required to be installed on the student's personal smart phone or tablet. A total of $76 \%$ stated that they found it easy to download the app, and $73 \%$ found it easy to use the app, but only $52 \%$ found it easy to add photos and notes to the game. The content of the game was highly rated in terms of suitability, easiness, and quality. Responses showed that $77 \%$ either strongly agreed or agreed that "the backstory was suitable and helped to frame the game", 76\% either strongly agreed or agreed that the "quality and suitability of images and video was high", and $84 \%$ either strongly agreed or agreed that "quiz questions were suitable". "Text was easy to read" received the highest rate ( $90 \%$ either strongly agreed or agreed), whereas "location interaction tasks were suitable (e.g., add a photo, find, or do something)" received the lowest rate (69\% either strongly agreed or agreed).

\section{Contribution to learning}

The main findings, shown in Figure 3 below, support our claim that LBMLGs provide a meaningful activity to enhance educational experiences. Students had the opportunity to visit real places and interact with both real and virtual content at each place. The great majority of the students (85\%) enjoyed the authenticity of learning in the real world and either strongly agreed or agreed that their experience was engaging (88\%), team building (74\%), pleasant being outdoors (88\%), an ice-breaker activity (61\%), and a fun way to learn (85\%). Slightly fewer students, however, either strongly agreed or agreed that the LBMLG helped them to either learn more about the topic $(67 \%)$, motivated them to do more research (54\%), or gave them the opportunity to practice different skills (61\%).

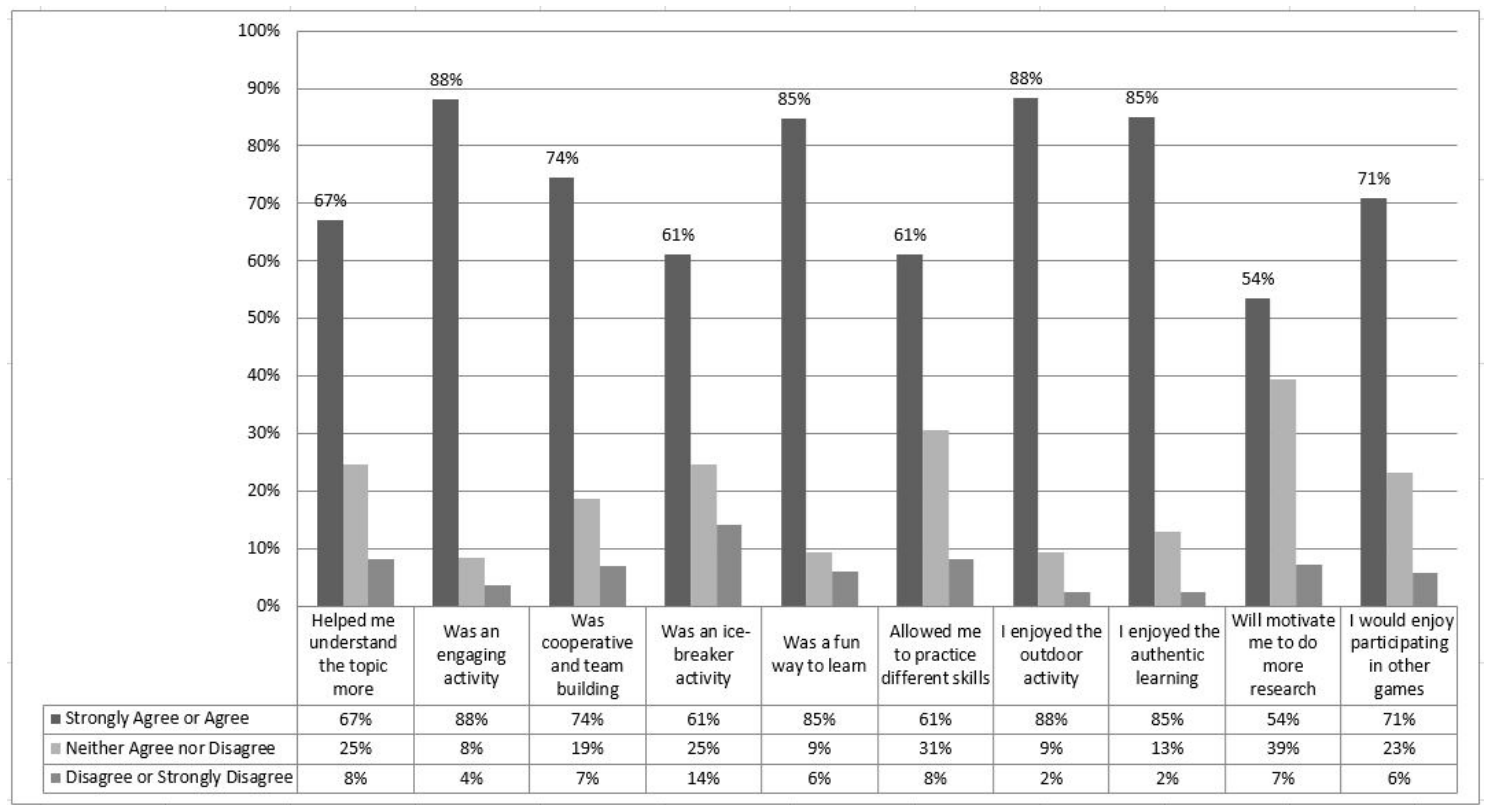

Figure 3. Analysis of online survey results for contribution to learning from players $(n=162)$

During focus group discussions, students mainly highlighted the problems they encountered during play, namely GPS failure, uploading photos and inclement weather conditions. They also mentioned that, even though they enjoyed working in teams, the game was more appealing for team members responsible for holding the phone, as team members with roles not requiring holding the phone had difficulty viewing content due to its small screen size. Forming small teams using at least one mobile device was our default arrangement for playing and students were encouraged to take on multiple roles, shown in Table 1, and to change them while they played. 
Table 1

Roles for students playing a LBMLG in a small team

\begin{tabular}{|l|l|}
\hline ROLE & DESCRIPTION \\
\hline Guard & The guard pays attention to the traffic and ensures there are no accidents. \\
\hline Navigator & The navigator has the mobile device and walks with it to each new place. \\
\hline $\begin{array}{l}\text { Director/camera } \\
\text { operator }\end{array}$ & $\begin{array}{l}\text { The director/camera operator is responsible for filming and taking photos on the } \\
\text { mobile device. }\end{array}$ \\
\hline Actor & The actor plays a lead role in photos. Sometimes many actors are required. \\
\hline Commander & The commander reads the task/activity ensuring everyone knows what to do. \\
\hline
\end{tabular}

Students also suggested that games would be more engaging if they were designed to be more competitive (i.e., by strengthening questions, initiating a sense of urgency such as time limits or bonus points for completion in certain time) or if they were being summatively assessed in their course.

\section{Study 2: Students as designers and developers}

In total, 209 students created LBMLGs in two courses: International Tourism: Predicting Markets and Opportunities, and Fitness and Lifestyle Management. The online survey was completed by 37 students. The games were played 70 times.

The age of the majority of the participants (86\%) ranged from 18 to 25 years. Of the participants, $65 \%$ had no prior experience in creating a LBMLG and $43 \%$ had no prior experience either in creating either a LBMLG or map on a web map service website.

\section{Student support}

A total of $49 \%$ of the students required a moderate amount of help and guidance in order to design and create a game and $32 \%$ of them required a lot or a great deal. The rest of the participants (19\%) only required a little help and guidance. The support offered was highly rated by the students. On average, the support provided during the lecture/workshop received the highest rate (84.5\%).

\section{Design and development}

Over half (54\%) of the participants found it either easy or extremely easy to plan the concept of their game whereas $27 \%$ of them found it neither easy nor difficult and $19 \%$ of them found it difficult. The students used a variety of sources to plan the concept of their games. Specifically, $54 \%$ of the students used website sources of information, $26 \%$ used textbooks, $6 \%$ used weblogs and social media sites, $3 \%$ used newspaper articles, $3 \%$ conducted interviews, and $9 \%$ relied on their personal experience and knowledge. The majority of the students $(72 \%)$ spent less than 2 hours to gather information and plan the concept of the game. Of the remainder, $14 \%$ of them reported that it took them 2 to 4 hours, $8 \%$ needed 4 to 6 hours, $3 \%$ spent 6 to 8 hours and 3\% spent a few days. Some 65\% found it either extremely easy or easy to create a game, using the Mobile Learning Academy game maker, 32\% found it neither easy nor difficult and only $3 \%$ found it difficult. In addition, $73 \%$ of them found it either extremely easy or easy to include multimedia into the game, $19 \%$ found it neither easy nor difficult and $8 \%$ found it difficult. The participants included images (89\%), videos (5\%), and graphics (3\%) into their games. A total of 51\% of the participants reported that it took them less than 1 hour to create their games, 22\% needed 1 to 2 hours, 16\% needed 2 to 3 hours and $11 \%$ spent 3 to 4 hours.

\section{Contribution to learning}

The majority of the participants either strongly agreed or agreed that designing and developing a mobile learning game was an engaging (84\%) a cooperative activity (84\%) and a fun way to learn (76\%). Most of them also either strongly agreed or agreed, that this activity gave them an opportunity to practice different skills (84\%) and implement their own ideas (84\%), and that they enjoyed developing a game for an authentic audience (78\%). Only 35\% of the students however either strongly agreed or agreed that the 
activity helped them understand more about the topic in their course, and 54\% reported that it motivated them to do more research about this topic in the future. Results are shown in Figure 4 below.

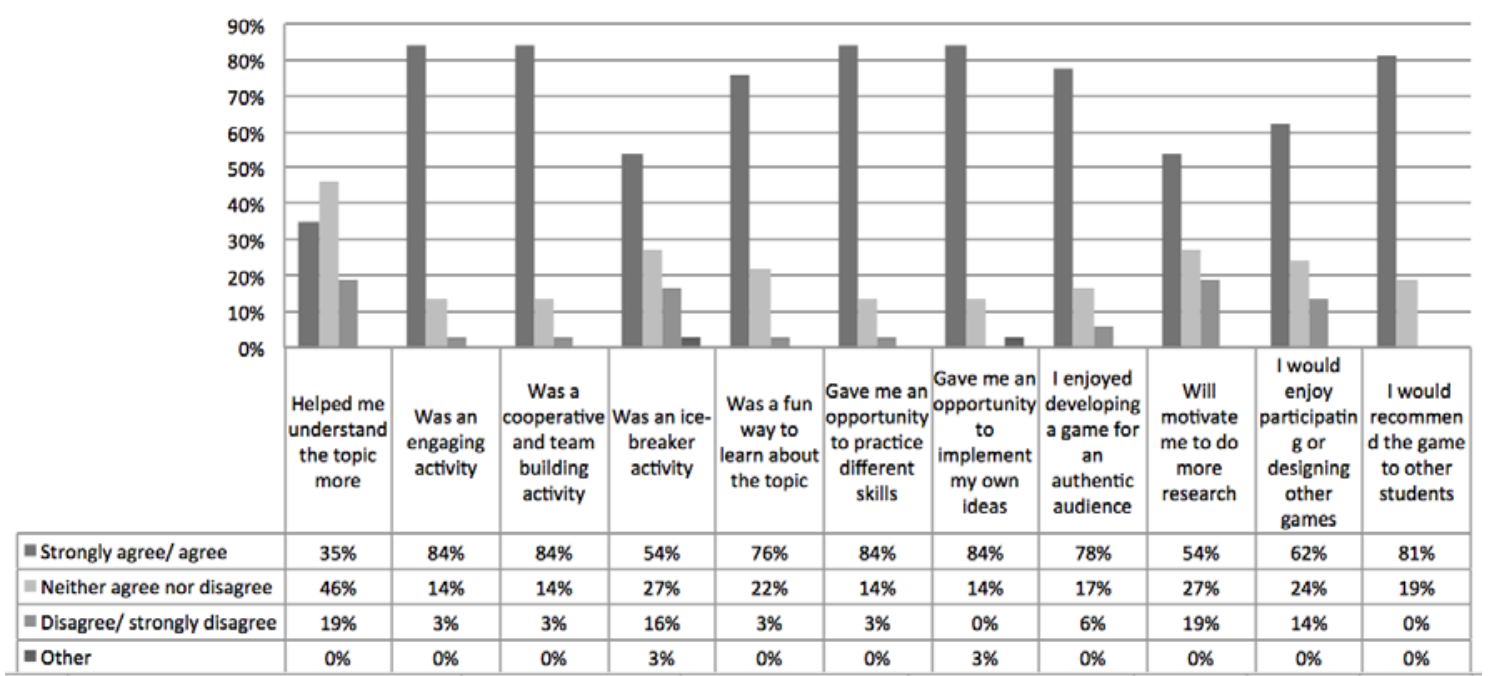

Figure 4. Overall results on the LBMLGs contribution to learning from student designers $(n=37)$

\section{Discussion}

In a side-by-side comparison between the games played by students, responses indicated wide-ranging agreement of the LBMLGs ability to deliver engagement, be an enjoyable outdoor experience, a fun way to learn, and an authentic learning experience (Figure 5). An important finding for deployment strategies is that this did not vary significantly among the games or across disciplines. However, there was a variation in responses to five of the questions. These were the LBMLGs:

- contribution to learning,

- $\quad$ capacity to deliver cooperative and team building processes,

- $\quad$ potential to be an ice breaker activity,

- $\quad$ ability to practice different skills, and

- $\quad$ being a motivator for further research on the topic.

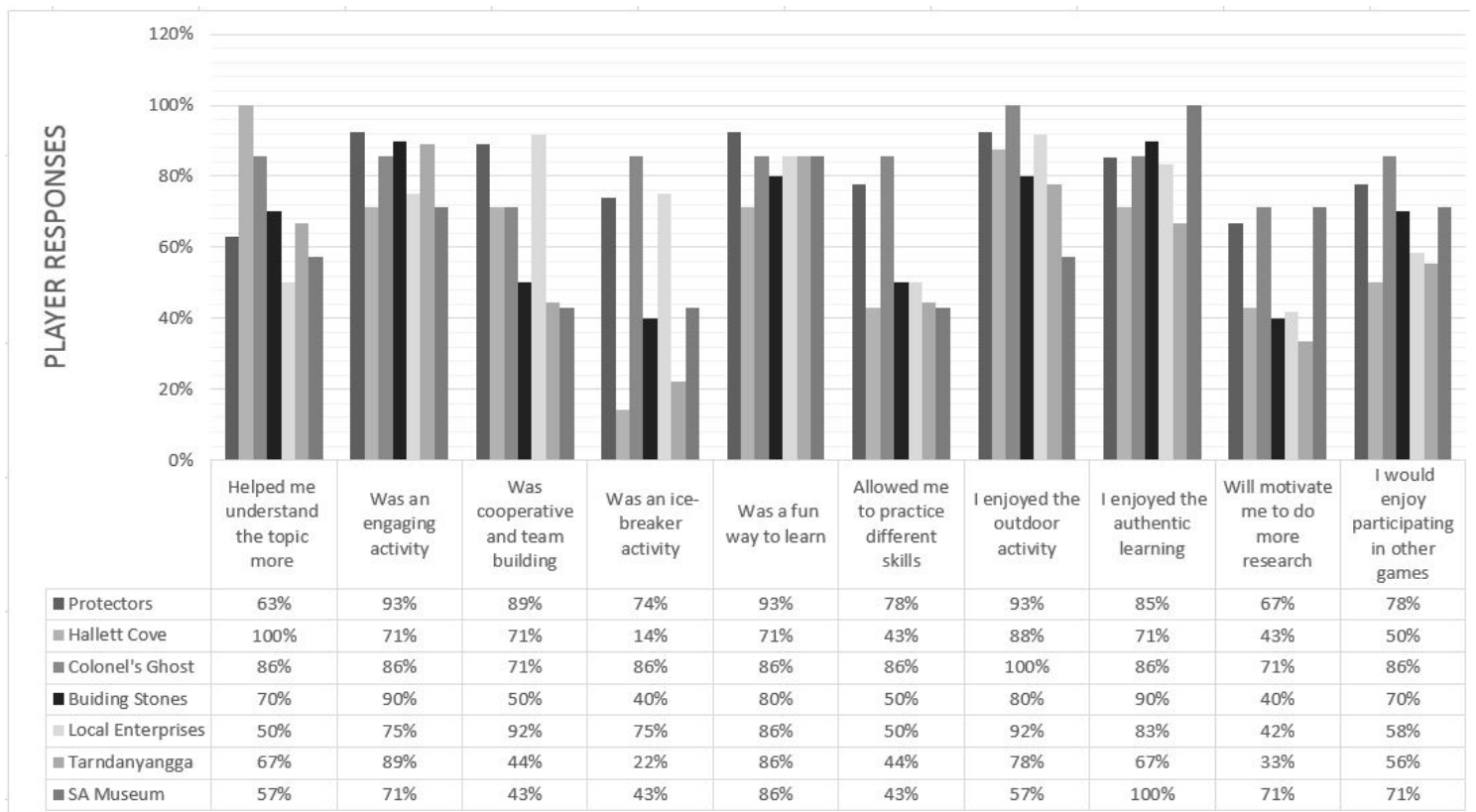

Figure 5. Comparison between games of the contribution to learning from players $(n=162)$ 
A side-by-side comparison between the two courses in which students designed games, showed three variations (Figure 6). These were the LBMLGs:

- contribution to learning,

- $\quad$ potential to be an ice breaker activity, and

- being a motivator for further design or play.

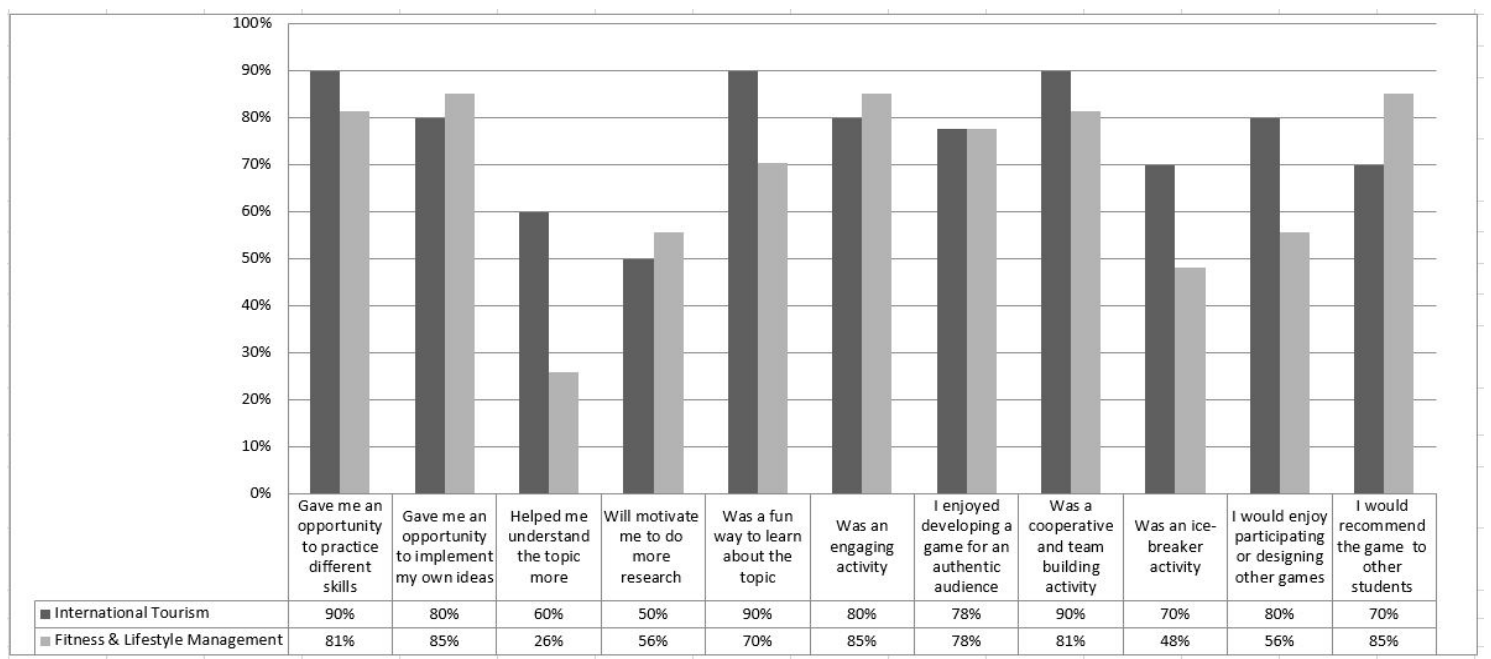

Figure 6. Comparison of the LBMLGs contribution to learning from student designers $(n=37)$

Some of the variations seen in the results between games are clearly evident. For example, whether the LBMLG was a good icebreaker activity, and a cooperative and team building variation, is likely to be related to when the students played the LBMLG (e.g., in their first tutorial or at a time after students got to know each other during the course). Other variations, including the important questions on whether the LBMLG helped students understand the topic more, in which responses varied from as high as $100 \%$ to low as $50 \%$, are less evident, but are likely related to the LBMLGs design and implementation strategy, its support from staff and challenges (e.g., technological, environmental, student characteristics) arising on the day. These are discussed in more detail in the sections below.

\section{Design}

When considering the design of an LBMLG, the strongest potential influencer of learning is the convincing interconnection that is developed between the narrative, the location-interaction tasks that support it, the gamification elements used, and how the experience is augmented by the use of rich digital media. In the online surveys completed after playing, students reported that they found the meaning and persuasion of the storyline created an emotional connection that engaged them. That, along with simple gamification methodologies and real-time location-interaction tasks (e.g., questions to answer, clues to find, puzzles to solve, items to collect), provided students with strong motivation and further engagement. This is in keeping with the findings from Avouris and Yiannoutsou (2012) that learning potential is related to the strong link between the narrative supported by the virtual world and physical action in the real world. It also aligns with the findings of Eliasson and Ramberg (2012), in which they state that a good design narrative can shift the focus of student attention from the mobile device to the physical world around them. Other design influencers reported by students that are likely to impact the benefits and adoption of an LBMLG, are its duration, level of difficulty, its location (city, rural, indoors outdoors), and its perceived competiveness.

\section{Integration}

The importance of course coordinators and tutors in implementing an LBMLG into a course cannot be underestimated. They play the key role in selecting the learning concept or topic to develop the LBMLG around, relating it back to course objectives and the graduate qualities (e.g., teamwork, communication skills, problem solving) the course promotes. We observed the LBMLGs that assisted students to understand their topic more were those that linked closely with learning outcomes and were integrated as 
seamlessly as possible into the course through its main goals and objectives. The relatively low result (26\%) for the item "helped me understand the topic more" for Fitness and Lifestyle Management shown in Figure 6 can be explained by the purpose of the LBMLG activity in the course. As stated previously in this paper, Fitness and Lifestyle Management students whose graduate aspirations include teaching, coaching, and/or health promotion were invited to design and develop a LBMLG primarily to extend their range of pedagogical strategies in preparation for their future employment. As a result, many of the games they designed were not specifically related to their course and were focused on many differing concepts, for example, health and fitness (44\%), an orientation tour of the campus (21\%), food (8\%), finding friends (12\%), and others (15\%). Focus group discussions with students following the activity revealed that students were generally enthusiastic in planning, developing, and trialing their own games. This high level of engagement extended to playing games designed by others and providing constructive feedback. They reported that the pedagogy of designing and developing LBMLGs heightened awareness of how they might use them with students in schools and or with young people in community activity programs.

\section{Method of engagement}

To satisfy OHSW requirements, some course coordinators chose to dedicate a small part (30 minutes) of a scheduled tutorial for students to play the LBMLG, allowing tutors to walk with students and exercise a duty of care. This often placed significant time constraints on play times. Many of our LBMLGs required a minimum of four or five locations to tell the story and develop the learning around the concept. Each location demands time for students to fully experience the content on the mobile device and to interact with it and the real world around them. Students reported that they found that interactions could not adequately yield learning if the time to complete the task was insufficient. One course coordinator dedicated an entire tutorial (2 hours) to the introduction and playing of the LBMLG. This approach returned results from the online survey that showed high levels of understanding, motivation, and engagement with the topic. Two course coordinators chose to deliver the LBMLG as a self-guided excursion and offered students a period of time (usually 1 to 3 weeks) in which to complete the activity. In this way students could work independently or in small groups at a time of their choosing. There was no time constraint to complete the game. Students using this approach also reported high levels of understanding about the topic by playing the LBMLG. In one course the LBMLG was used to prepare students for an upcoming field excursion. It was designed in a genre that allowed students to visit the location virtually both before and after the actual field trip. It was used by students as a means to optimise their learning before the real field trip and to consolidate their experiences afterwards. Results from the online survey indicate students highly appreciated using the LBMLG as a learning object to help them understand the topic.

\section{Physical challenges}

As Sailer, Schito, Kiefer, and Raubal (2015) note, the successful delivery of LBMLGs is highly complex because of the volatile challenges the environment, technology, and students all bring to the mobile learning ecosystem. Our design strategy needed to take into account safety risks associated with traffic conditions and accessibility of locations. Decisions of whether to play under adverse weather conditions (e.g., heat, rain, wind), all required confident handling by those responsible for the student's welfare. We found that student evaluations of their experience playing an LBMLG in extreme heat were generally poorer than when weather conditions were more amicable. Students used their personal mobile devices to play our LBMLGs, therefore several technological factors were out of our control. Each time an LBMLG was played, a very small number of mobile devices would not install the mobile app, would lose internet connectivity, GPS signals became inaccurate or irregular, and uploads of photos to the game server did not function correctly. When an online educational designer was in attendance some of these issues could be resolved just-in-time, particularly if all students began playing the game at the same start location. Other hardware issues we encountered were associated with mobile screen reflection in bright sunshine making content difficult to view and network/mobile data irregularities. Students were encouraged to download the game and its content either at home or using the university's wi-fi network before beginning to play. This enabled rich media content (e.g., video) to stream locally while playing and limited the consumption of prepaid mobile data (and its associated costs) for the uploading of photos and posting of reviews within the apps whilst playing. When individual technological issues could not be resolved students were encouraged to join a team where at least one mobile device was functioning correctly. 


\section{Staff support}

Motivation is a key factor in learning. While most students eagerly embraced playing and designing LBMLGs in their course, the support of a tutor and/or course coordinator and the technological and pedagogical support of an online educational designer to prepare students, motivate them whilst playing or designing and followed up with them afterwards, all contributes to the enhancing the educational experiences associated with using LBMLGs as a teaching and learning methodology.

\section{Conclusion and future work}

Our study indicates that both the playing and designing of LBMLGs by students can provide benefits by delivering active, engaging, and authentic educational experiences, which enhance the opportunities to interact with locations, online content, and with each other. Both students who play games designed by others and students who design and develop their own LBMLGs are building and applying their knowledge in an authentic context, creating engaging, personal, and meaningful learning experiences. In doing so, they have enriched opportunities to improve their communication and collaboration skills, digital literacy, spatial awareness, and social skills. We found evidence in our online surveys that designing LBMLGs offers students an opportunity to identify and implement new ICT and online research skills (e.g., managing, operating, and applying ICT) as they conceptualised, developed, and implemented their own ideas. We found no significant integration issues while maintaining these benefits across disciplines, indicating that there exists generalisability in the integration and adoption of LBMLGs in higher education. We therefore have confidence in the ability to develop institution wide deployment frameworks in the future.

We aim to expand the breadth of our investigations regarding the benefits and best practice deployment options of both playing and students designing LBMLGs. New opportunities to widen their applicability in both face-to-face and fully online courses are currently being explored, as we develop a framework to guide the process of implementing LMBLGs as a scalable approach to learning.

Our website http://pedago.online contains ongoing information regarding our deployment frameworks and research.

\section{Acknowledgements}

The research involved in this study received funding from a Teaching and Learning Grant from the University of South Australia Digital Learning Strategy 2015-2020. It has been granted E2 Level Ethics approval (Application ID: 36104) and meets the requirements of the National Statement on Ethical Conduct in Human Research. Data collected through surveys is being used to inform improvements at the University and can also be used in external publications and presentations.

\section{References}

Alnuaim, A., Caleb-Solly, P., \& Perry, C. (2012). Location-based mobile learning for higher education students - developing an application to support critical thinking. Proceedings of the 11th International Conference on Mobile and Contextual Learning 2012, Helsinki, Finland, 328-331.

Ardito, C., Sintoris, C., Raptis, D., Yiannoutsou, N., Avouris, N., \& Costabile, M. F. (2010). Design guidelines for location-based mobile games for learning. Proceedings of the International Conference on Social Applications for Lifelong Learning, Greece, 96-100.

Avouris, N. M., \& Yiannoutsou, N. (2012). A review of mobile location-based games for learning across physical and virtual spaces. Journal of Universal Computer Science 18(15), 2120-2142.

Baik, C, Naylor, R., \& Arkoudis, S. (2015). The first year experience in Australian universities: Findings from two decades, 1994-2014. Retrieved from http://fyhe.com.au/wp-content/uploads/2015/03/FYE2014-FULL-report-FINAL-web.pdf: 1-110. 
Buote, V. M., Pancer, S. M., Pratt, M. W., Adams, G., Birnie-Lefcovitch, S., Polivy, J., \& Wintre, M. G. (2007). The importance of friends: Friendship and adjustment among 1st-year university students. Journal of Adolescent Research, 22(6), 665-689. https://doi.org/10.1177/0743558407306344

Cochrane, T. D. (2014). Critical success factors for transforming pedagogy with mobile Web 2.0. British Journal of Educational Technology, 45(1), 65-82. https://doi.org/10.1111/j.1467-8535.2012.01384.x

Edmonds, R. K., \& Smith, S. (2016). Location-based mobile learning games: Motivation for and engagement with the learning process. Proceedings of the 15th International Conference on Mobile and Contextual Learning 2016, Sydney, 72-76.

Eliasson, J., \& Ramberg, R., (2012). Design guidelines for location-based and contextual learning supported by mobile devices. International Journal of Handheld Computing Research, 3(2), 26-43. https://doi.org/10.4018/jhcr.2012040102

Huizenga, J., Admiraal, W., Akkerman, S., \& Ten Dam, G. (2007). Learning history by playing a mobile city game. Proceedings of the 1st European Conference on Game-based Learning, Paisley, 127-134.

Hwang, G., Po-Han Wu, P., Chen, C., \& Tu, N. (2016) Effects of an augmented reality-based educational game on students' learning achievements and attitudes in real-world observations, Interactive Learning Environments, 24(8), 1895-1906, http://dx.doi.org/10.1080/10494820.2015.1057747

Johnson, L., Adams Becker, S., Estrada, V., \& Freeman, A. (2015). NMC Horizon Report: 2015 Higher Education Edition. Austin, TX: The New Media Consortium.

Knight, J., Corbett, A., Smith, C., Watkins, B., Hardy, R., \& Jones, G. (2012). What made me stay?” A review of the reasons student nurses enrolled in a Bachelor of Nursing programme completed their studies: A descriptive phenomenological study. Nurse Education Today, 32(8): e62-e65. https://doi.org/10.1016/j.nedt.2012.03.007

Liu, T. Y., \& Chu, Y. L. (2010). Using ubiquitous games in an English listening and speaking course: Impact on learning outcomes and motivation. Computers \& Education, 55(2), 630-643. https://doi.org/10.1016/j.compedu.2010.02.023

Murphy, A., Farley, H., \& Koronios, A. (2013). Understanding the use of smart mobile technologies for learning in higher education Proceedings of the 30th Australasian Society for Computers in Learning in Tertiary Education Conference, Sydney, 602-606.

Priestnall, G., Brown, E., Sharples, M., \& Polmear, G. (2010). Augmenting the field experience: A student-led comparison of techniques and technologies. In E. Brown (Ed.), Education in the wild: Contextual and location based mobile learning in action (pp. 43-46). University of Nottingham: Learning Sciences Research Institute.

Rogers, Y., Sharp, H., \& Preece, J. (2011). Interaction design: Beyond human-computer interaction. United Kingdom: John Wiley \& Sons.

Sailer, C., Schito, J., Kiefer, P., \& Raubal, M. (2015). Teachers matter: Challenges of using a locationbased mobile learning platform. Proceedings of International Conference on Mobile and Contextual Learning, Venice, 239-255. https://doi.org/10.1007/978-3-319-25684-9_18

Sharples, M. (2002). Disruptive devices: Mobile technology for conversational learning. International Journal of Continuing Engineering Education and Life Long Learning, 12(5-6), 504-520. https://doi.org/10.1504/IJCEELL.2002.002148

Sigala, M. (2015). The application and impact of gamification on trip planning and experiences: The case of TripAdvisor's funware. Electronic Markets: The International Journal of Networked Markets, 25(3), 189-209. https://doi.org/10.1007/s12525-014-0179-1

Slussaref, M., \& Boháčková, P. (2016). Students as game designers vs. ‘just’ players: Comparison of two different approaches to location-based games implementation into school curricula. Digital Education Review, 29, 284-297.

Thomas, L. (2012). Building student engagement and belonging in higher education at a time of change: Final report from the "What Works?" student retention and success programme. UK Higher Education Academy. Retrieved from https://www.heacademy.ac.uk/system/files/what_works_final_report.pdf.

Veelo, K. (2007). Games atelier - Learning environment for producing and playing location-based mobile games. (Masters thesis, University of Twente, Netherlands).

Visscher-Voerman, I., Gustafson, K., \& Plomp, T. (1999). Educational design and development: An overview of paradigms. In J. van den Akker, R. M. Branch, K. Gustafson, N. Nieveen, \& T. Plomp (Eds.), Design approaches and tools in education and training (pp. 15-28). Boston, MA: Kluwer Academic. https://doi.org/10.1007/978-94-011-4255-7_2 
Wijers, M., Jonker, V., \& Drijvers, P. (2010). MobileMath: Exploring mathematics outside the classroom. Zentralblatt für Didaktik der Mathematik, 42(7), pp.789-799. https://doi.org/10.1007/s11858-010$\underline{0276-3}$

Corresponding author: Roger Edmonds, roger.edmonds@unisa.edu.au

Australasian Journal of Educational Technology (c) 2017.

Please cite as: Edmonds, R., \& Smith, S. (2017). From playing to designing: Enhancing educational experiences with location-based mobile learning games. Australasian Journal of Educational Technology, 33(6), 41-53. https://doi.org/10.14742/ajet.3583 